\title{
A Comparative Concept Study and Evaluation for New Broadband Noise Absorbing Acoustic Liner Concepts for Civil Aviation
}

\author{
Marcel Mischke \\ Brandenburg University of \\ Technology \\ Cottbus-Senftenberg \\ Marcel.Mischke@b-tu.de \\ Cottbus, Brandenburg, Germany
}

\author{
Stefan Kazula \\ Brandenburg University of \\ Technology \\ Cottbus-Senftenberg \\ Stefan.Kazula@b-tu.de \\ Cottbus, Brandenburg, Germany
}

\author{
Klaus Höschler \\ Brandenburg University of \\ Technology \\ Cottbus-Senftenberg \\ Klaus.Hoeschler@b-tu.de \\ Cottbus, Brandenburg, Germany
}

\begin{abstract}
This paper presents the application of a concept evaluation of two broadband acoustic liners for future aviation. Requirements, design and functions of these liner concepts are introduced. A suitable evaluation method is described and conducted. The results of the evaluation are discussed and further tasks are pointed out.
\end{abstract}

\section{INTRODUCTION}

The European Union has defined targets for future aviation and hence research goals by providing the "FlightPath 2050" [01]. Thus, the aviation industry are constantly improving existing and developing new innovative technologies to stay competitive in line with these targets. An important field of improvements of the defined goals is the reduction of noise emitted by aircrafts and aero engines.

In recent years significant improvements have been realised for the subsystems of aircraft engines to achieve the permitted goals for noise emission. These improvements result in reduced noise of aero engines with an increasingly broadband and low-frequency character. Due to this character, current narrowband acoustic liners are unable to comply with noise requirements for future aviation [01]. This challenge can be tackled by further developing subsystems of the aero engine, e.g. the compressor system, as well as the development of innovative noise treatment solutions, e.g. broadband acoustic liners.

As part of the LaKS project (Lärmabsorbierende Kunststoffstrukturen / Noise Absorbing Composite Structures), Höschler et al. [02] present the design of one broadband acoustic liner concept. A significant increase of the broadband noise reduction and a shift of the integral damping curve into a low frequency range can be achieved by utilizing these concepts, which integrate flexible structures into acoustic liners [03].

In this paper,

- the concept evaluation process is introduced,

- the requirements of broadband liner concepts are presented and

- the concepts are evaluated concerning the identified requirements.

The concept evaluation has been conducted by all LaKS project partners to enable a comprehensive and objective assessment.

\section{METHODOLOGY OF PRODUCT DEVELOPMENT}

The analysis, the rating and the evaluation of concepts, systems and methods are essential parts of the product development process. These can be achieved

- by specifying requirements, e.g. by means of guidelines and checklists,

- by defining functions, e.g. by means of morphological boxes and design catalogues, and

- by several selection and rating methods [04], [05].

Figure 1 presents the rating and evaluation process, which has been applied to broadband acoustic liner concepts.

\section{Requirements Definition}

Depending on the product type, later application area and degree of innovation, the definition of requirements can be more or less extensive. The requirements should be defined in a meaningful but also as short as possible way. They represent the TARGET-properties of the finished product to be developed and should be reflected by the IS-properties of the product under development which are adapted during the development process [04]. 


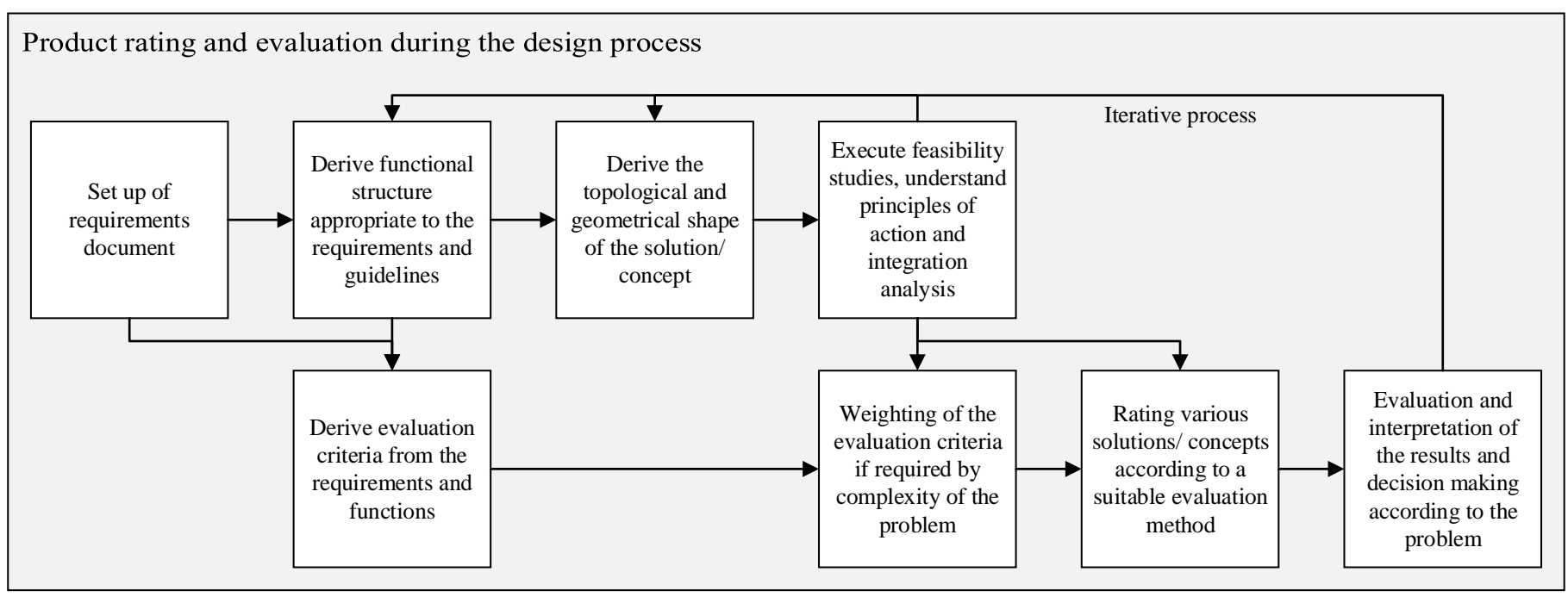

Figure 1: Product rating and evaluation during design process according to [04], [05], [06]

In order to find suitable requirement criteria, various methods and tools such as

- Classification lists,

- Guidelines,

- Question lists and questionnaires,

- Clarification of tasks in an interdisciplinary team

can be applied to find suitable requirement criteria [04], [06], [07], [08], [09].

Two of these methods have been selected to define the requirements of the liner concepts designed for aviation and are introduced in the following.

\section{Guideline:}

The requirements for the novel broadband acoustic liners are based on the requirement profile of existing acoustic liners, due to the planned application in aviation. It is reasonable to include the aviation regulations and guidelines provided by the aviation authorities EASA (European Aviation Safety Agency) and FAA (Federal Aviation Administration). In case of the EASA the Certification Specification CS-25 (Large Aeroplanes) [10], the CS-E (Engines) [11] and the CS-36 (Aircraft Noise) [12] are applicable.

\section{Clarify the tasks in an interdisciplinary team:}

New liner subcomponents, e.g. the flexible structures, call for additional requirement to the state of the art for acoustic liners. The missing requirements could be identified due to the expertise of the respective LaKS project partners in different disciplines.

Depending on the scope of the list of requirements, Ehrlenspiel [04] recommends to subdivide the individual requirement points into concise categories. While more requirements have been identified, the following eight requirements from four different disciplines are utilized for the analysis and evaluation of the broadband acoustic liner concepts. A similar approach for a safe design process and function analysis in aviation has been applied by [13], [14].
- $\quad$ Functionality (acoustic)

Narrowband Attenuation (N): Ability of the liner system to damp noise at a specific design frequency (maximum damping possible).

Broadband Attenuation (B): Ability of the liner system to attenuate noise over a wide frequency band (the highest possible integral attenuation measure).

\section{- Structural integrity}

Operational Stress (O): Resistance of liner structures (rigid and flexible structures) against mechanical stress during operation (vibrations, impacts, etc.).

Environmental Influence (E): Resistance of liner structures (rigid and flexible structures) against environmental influence (sun, rain, etc.).

\section{- Integrability}

Drainage- und Ventilation (D): Ability of the liner system to drain liquids (drainage) and gases (ventilation).

Aerodynamic Efficiency (A): Surface and shape quality of the flow facing face sheet. Measure for the possible disturbance of the air flow (boundary layer behaviour, turbulence, etc.).

\section{- Economy}

Design Space and Weight (D): Acoustic liners are additional systems to comply with the regulations of the CS-36 [12]. As they are not absolutely necessary for flight operations, attention must be paid to lightweight design and minimum use of installation and design space.

$\underline{\text { Reliability and Life Cycle Costs }}(\mathbf{R})$ : The replacement or repair of defect in-service liner segments is not intended. Usually they stay in operation as long as the engine itself. The reliability and life cycle costs should be correspondingly high.

In the last step of the requirement definition, the eight requirements found are converted into evaluation criteria by using top-down target derivation. These criteria are 
supplemented by a functional and preliminary system safety analysis [15].

\section{Functional Analysis}

Ehrlenspiel [04] and Berding [07] describe the main function of a product as the sum of all required sub-functions. These sub-functions result from the previously determined safety and functional requirements, as well as the respective customer requirements.

Mischke et al. [15] use a general approach according to VDI 2803 [16] for the functional analysis of the liner structure. This approach combines the requirements and resulting functions directly with the design architecture of the system.

The functional analysis according to ARP (Aerospace Recommended Practices) 4754 [17] does not provide a direct transfer of the function into a system architecture. This deductive method of the ARP 4754 has been enhanced to an extent, where the system architecture is defined, compare Figure 2.

The definition of the term "main function" of Ehrlenspiel and Berding can be linked to the ARP 4754 using a bottom-up methodology and assigned to the previously collected product requirements.

\section{Principles of Action, Feasibility and Integration}

A first topological and geometric concept for the flexible broadband liner concepts can be derived through the functional structure according to ARP 4754 [17] that has been extended by sub-system components. Figure $3 \mathrm{a}$ presents a state of the art narrow-band acoustic liner utilizing a sandwich design with a rigid honeycomb core (SHR-Liner; Standard Helmholtz Resonator Liner).

Figure $3 \mathrm{~b}$ shows the structure of the FHR-Liner (Foil Helmholtz-Resonator Liner), which is quite similar to the SHR-Liner. The only difference present flexible foil structures that are integrated into the walls of the honeycomb core. Their application results from the sub-function "Reduce Noise" in Figure 2. Knobloch et al. [03] show that the flexible foil elements of the FHR-Liner cause a significant increase of the integral damping factor compared to the basic structure of the SHR-Liner. Additionally, a shift of the damping curve into the low-frequency range has been demonstrated [03].

Figure 3c introduces the PR-Liner (Plate Resonator Liner) concept from Kisler et al. [18] for increasing broadband damping in aircraft engines. This concept can be derived from the sub-function "Reduce Noise" of Figure 2. It can be seen that the perforated face sheet of the SHR-Liner has been almost completely replaced by a flexible foil layer. The acoustic functionality of this liner concept has also been demonstrated by Knobloch through wind tunnel tests.

Due to the significant structural differences of FHR- and PR-Liners compared to SHR-Liners, it has to be proven that the sub-function „maintaining structural integrity“ can be achieved by the new liner concepts. For that purpose Bubner [19] performed extensive structural analyses and geometric design variations based on the geometries of the FHR- and the PR-Liners.

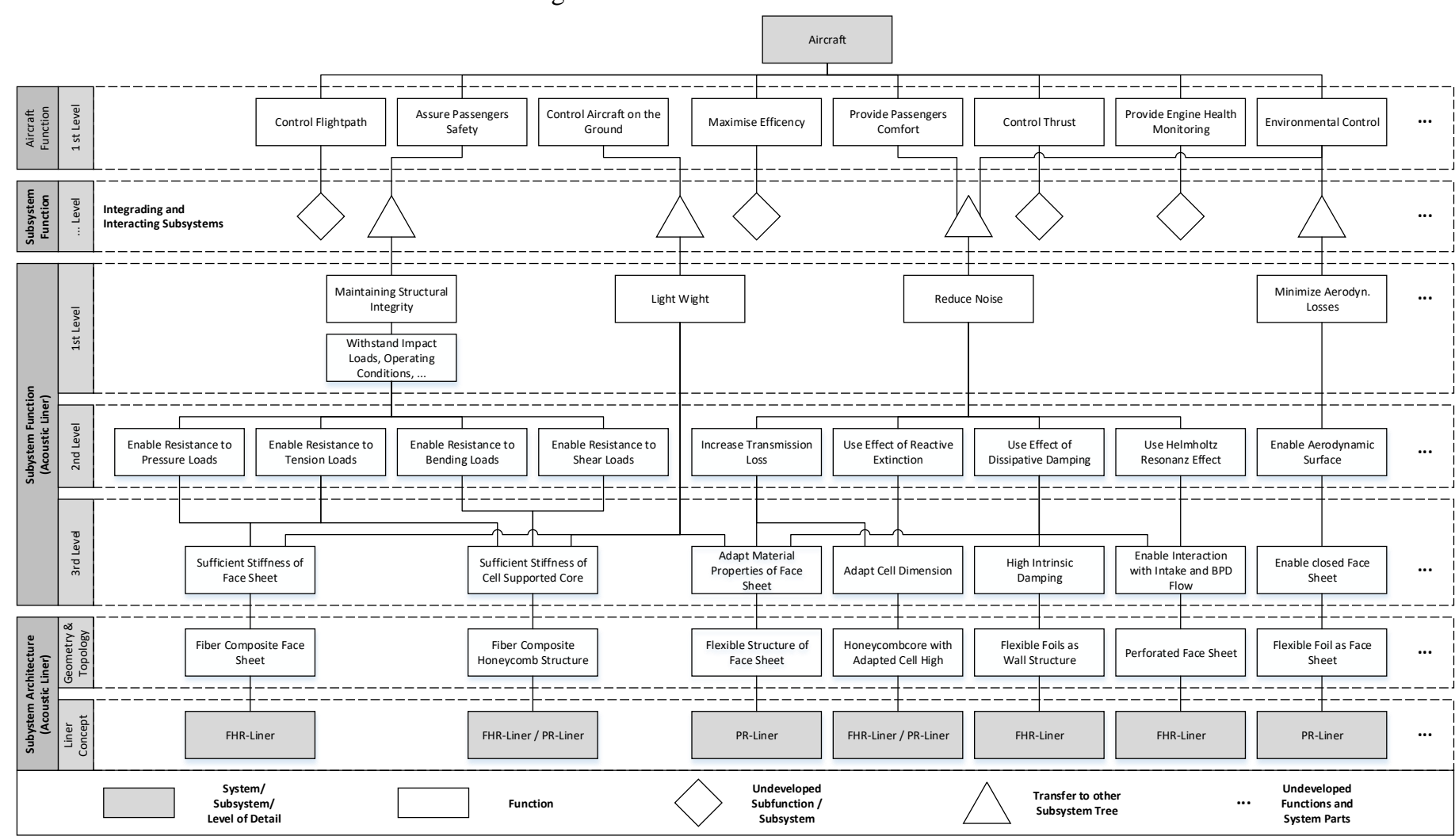

Figure 2: Functional analysis according to ARP4754 [17] with extended approach to system architecture 


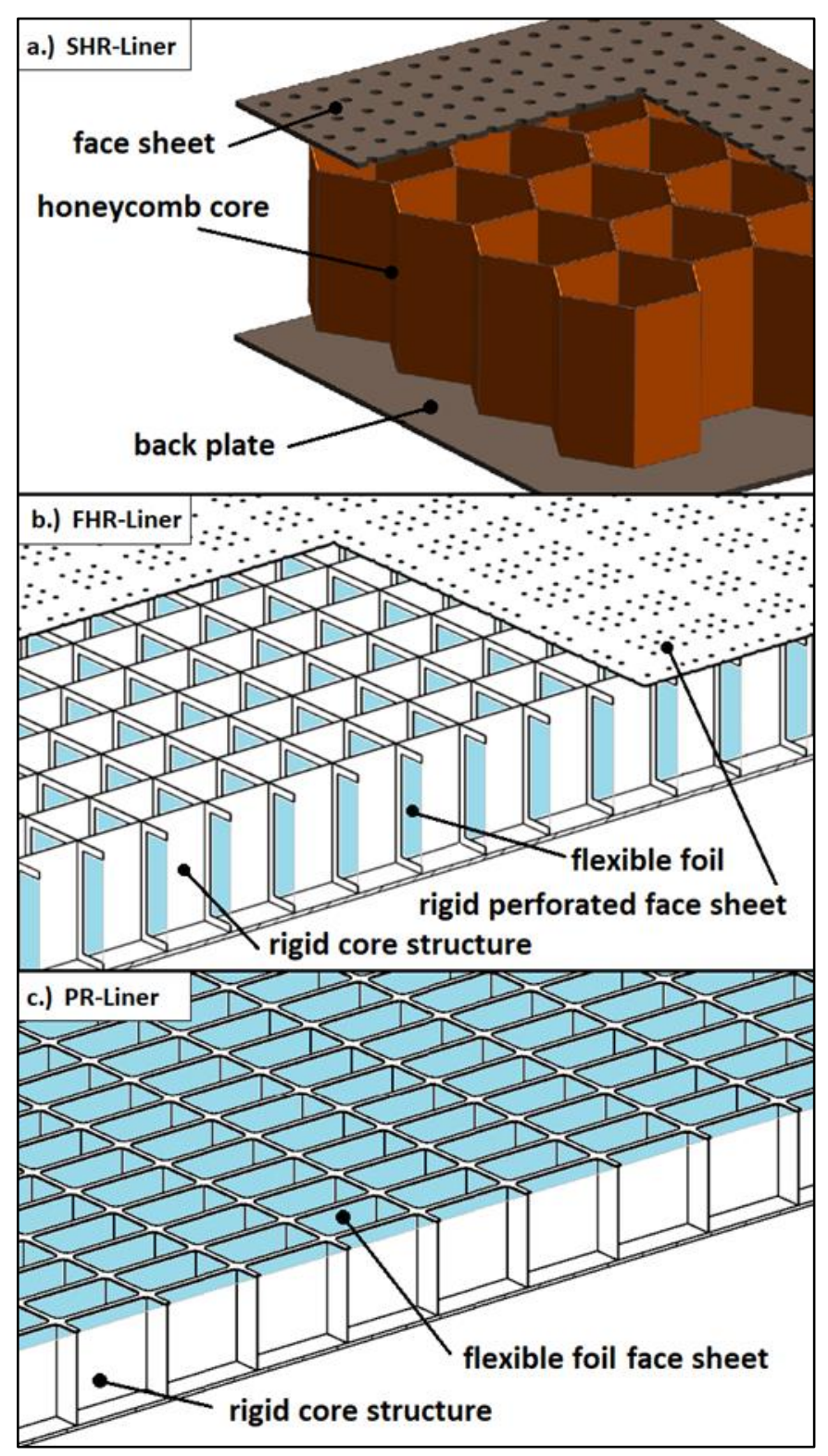

\section{Figure 3: Current acoustic liner and new liner concepts with flexible structure}

Mischke et al [15] have conducted a preliminary system safety analysis according to the approach of ARP 4761 [20], to assess the safety aspects of the FHR- and PR-Liner. A similar approach has been applied in comparable feasibility studies for safe innovative concepts in aviation [21], [22], [23].

The results of the functional acoustic investigations of Knobloch [03] and Kisler [18], as well as Bubner's structural analysis [19] and Mischke's system safety assessment [15] provide the input for the knowledge-based concept evaluation of the broadband acoustic liner concepts.

\section{Weighting of Evaluation Criteria}

For a more objective rating and evaluation of systems in the early product development process, it can be useful to weight the requirements if it is permitted by the rating method and the state of knowledge.
Lindemann [06], as well as Feldhusen and Grote [09] recommend performing the weighting of complex products in an integrated group of different disciplines. This approach is ideal for the multidisciplinary character of the rating and evaluation study of the acoustic liner concepts.

Different weighting methods such as

- the hierarchical weighting [06],

- weighting by target preference matrix [07], [09],

- the weighting by means of influence matrix [09] and

- the weighting by ranked space method [24]

can be used.

A combination of hierarchical weighting and ranked space method is selected to prepare the rating and evaluation of the liner concepts. Through the hierarchical weighting approach, the weighting and evaluation criteria derived from the requirements are subdivided into the three categories (MEC; Main Evaluation Categories):

- Acoustics,

- System Safety and Integration, as well as

- $\quad$ Structure and Material.

The eight evaluation criteria are identical in each MEC. However, due to the different technical orientation of the MEC, the weightings of the criteria are varied in each of them. This enables that different main functions and several critical evaluation points are formed for each MEC.

The final weighting is carried out by means of ranked space method and separately for each individual MEC to increase the objectivity. When using the ranking method of Breiing and Knosala [24] for the weighting, all evaluation criteria are compared against each other in a matrix. If the row criterion is more important than the column criterion, the corresponding cell is assigned the value 2 . In the case of a lower priority, a "0" occurs. If both evaluation criteria are equally important, the value " $1 "$ is assigned.

By counting and normalizing all achieved points of a row criterion $\left(\mathrm{p}_{\mathrm{i}}\right)$ according to equation 1 , an objective weighting factor $\left(\mathrm{w}_{\mathrm{i}}\right)$ and a corresponding rank of the considered criterion can be defined.

$$
w_{i}=p_{i} / P
$$

Figure 4 shows the summary of the weighting in the ranking procedure. The difference between the weighting factors obtained on the different MECs becomes clear.

Depending on the MEC, the weighting of the criteria may vary. For a pure acoustic-functional rating and evaluation, the evaluation criteria "broadband attenuation" can be considered more important than sensitivity to the criteria "environmental influences". If the emphasis was on "system safety and integration", it would be exactly the opposite, as noise reduction is not a relevant criterion for aviation safety.

The weightings of the three MECs have been distributed among the LaKS project partners, in order to maintain the objective and knowledge-based character of the evaluation. Each project partner has weighted the criteria in its own field 


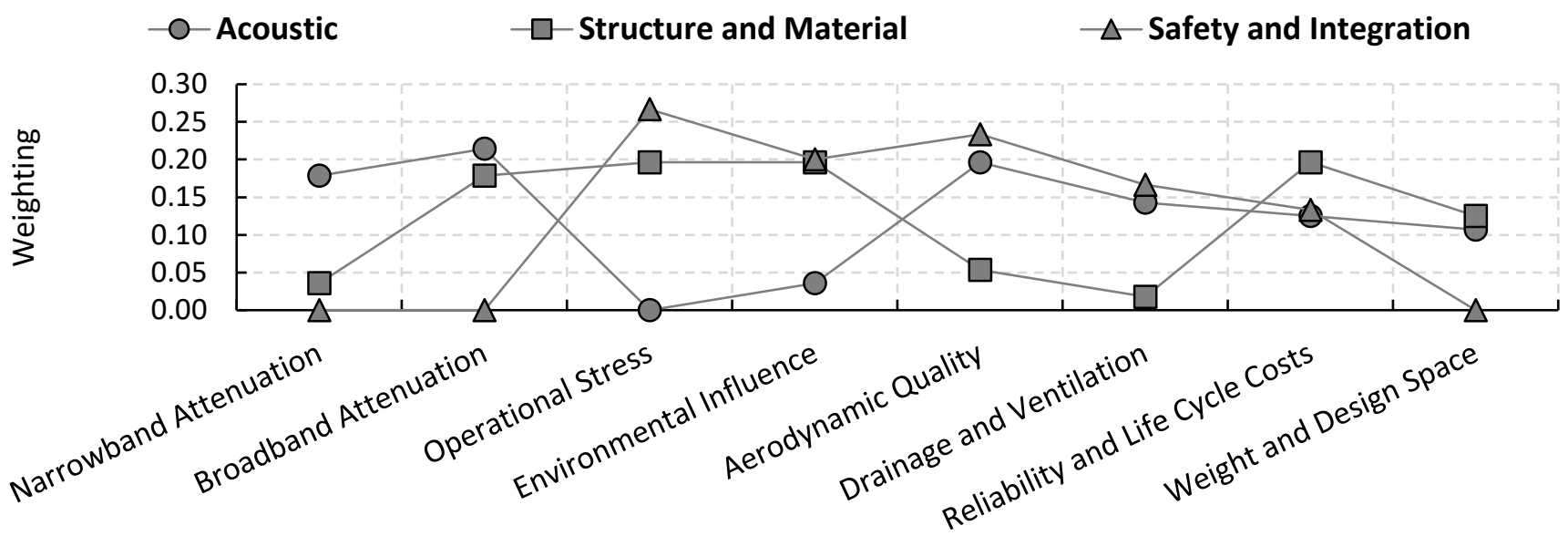

Figure 4: Difference in weighting of evaluation criteria on three MEC

of expertise and supported the colleagues at multidisciplinary interfaces.

\section{Concept Rating}

Evaluation procedures can be used to analyse and compare proposed solutions for a specific problem. Feldhusen and Grote define "rating and evaluation procedures" as generally applicable methods to support decision-making processes [09]. A selection is made between different targetoriented product variants or partial solutions. A wide range of potential evaluation methods can be used for this purpose. With increasing complexity and time, the most common procedures are

- the balance of arguments,

- the rating using selection lists,

- the pairwise comparison,

- the simple point rating,

- the weighted point rating,

- the technical-economic rating according to VDI guideline 2225 and

- the cost-benefit analysis [04], [06], [07], [09], [25], [26].

When selecting a procedure, it should be noted that the required time and the complexity of a rating procedure should always be in reasonable relation to the quality of the evaluation statement and complexity of the decision problem.

Due to the early development stage of FHR- and PR-Liner (Technology Readiness Level; TRL 2-3), the choice of a complex rating such as the cost-benefit analysis according to Zangemeister [26] or the technical-economic rating according to VDI 2225 [25] is not expedient. In most cases, background information are still missing at the beginning of a development, averting to carry out a meaningful rating and evaluation. However, VDI 2225 recommends to supplement open questions in the rating and evaluation process with meaningful and reasonable assumptions [25]. This makes sense if the cooperation of corresponding scientific departments can be used for different technical questions. Accordingly in the LaKS joint project, the weighted point rating is selected for the rating and evaluation of FHR- and PR-Liner concepts.

Within the framework of the weighted point rating, the product variants, concepts or solution principles are analysed according to the previously defined evaluation criteria. The extent to which the product fulfils the respective evaluation criterion is checked. An evaluation scale of 0 to 4 can be selected for early development stages with less background information on the product and principles of action or an evaluation scale of 0 to 10 for products with a higher development stage [09], [25]. The final value of the distributed rating points is determined by the previously created weighting (within this paper by the ranked space method) of the evaluation criteria. According to equation 2, the relative rating of a concept $r_{i}$ results from the product sum of the degree of criteria fulfilment $m_{i, j}$ (can be from 0 to 4 ) and the weighting factor $w_{i}$ (Figure 4 ) divided by the maximum achievable number of points of the degree of criteria fulfilment (here a maximum of 4 ).

$$
r_{i}=\frac{1}{4} \cdot \sum_{i=1 ; j=1}^{l ; k} m_{i, j} \cdot w_{i}
$$

As a result of the low TRL of the broadband liner concepts, an evaluation scale from 0 to 4 is selected. The SHR-Liner is assigned an average degree of implementation $\mathrm{m}_{\mathrm{i}, \mathrm{j}}=2$ in all criteria based on VDI 2225 [25]. This is done to obtain a corresponding comparison of the new acoustic liner concepts with the currently in service SHR-Liner. The resulting rating scale for FHR- and PR-Liner is listed below.

- „---“ or 0 point $\rightarrow$ criteria fulfilment much worse than with the SHR-Liner

- ,-“" or 1 points $\rightarrow$ criteria fulfilment worse than with the SHR-Liner

-, $\mathrm{O}^{\circ}$ or 2 points $\rightarrow$ criteria fulfilment as good as with the SHR-Liner

- $\quad,+{ }^{+*}$ or 3 points $\rightarrow$ criteria fulfilment better than with the SHR-Liner

-,++ " or 4 points $\rightarrow$ criteria fulfilment much better than with the SHR-Liner 
Figure 5 shows the degree of criteria fulfilment $m_{i, j}$ by the FHR- and PR-Liner in comparison to the reference liner (SHR-Liner). The selection of the degree of implementation in Figure 5 was made by information from

- the state of the art [27], [28], [29],

- investigations on the principles of action [03], [18],

- $\quad$ analyses of system safety and aspects of integration in the aero engine [15], [30]

- research of technical literature [31], [32], [33] and

- information exchange of project partners from different technical disciplines.

The calculated relative rating of the three different MECs for the two liner concepts compared to the SHR-Liner can be seen in Figure 6.

\section{EVALUATION AND INTERPRETATION OF RESULTS}

The results of a product rating should only serve as a tool for the decision maker to assess all contingencies and risks within the appropriate framework. It should be noted that all decisions are subjective despite the prior objective and knowledge-based weighting, rating and evaluation [09], [04].

\section{Evaluation of the MEC}

The subdivision into different MECs clearly shows that the weighting factors of the individual evaluation criteria vary significantly (Figure 4). The exclusion criteria of the individual MECs can be quickly identified. For example, from a functional-acoustic point of view, the weighting attaches great importance to narrowband and broadband noise reduction, as well as to an aerodynamic surface. On the other hand, in terms of safety, the weighting factor for noise reduction is 0 because noise has no safety effects. On this position, the evaluation criterion "Operational Stress" assumes a very high weighting factor. This shows that failure of the structure due to static or dynamic loads during flight could

a.) FHR-Liner

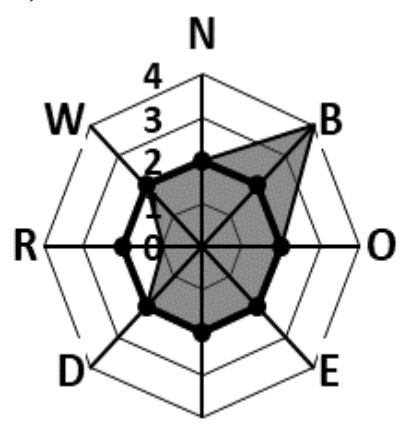

A

FHR-Liner

Narrowband Attenuation (N)

Operational Stress (O)

Aerodynamic Quality (A)

Reliability and Life Cycle Costs (R) Weight and Design Space (W)

Figure 5: Criteria fulfilment of the liner concepts have a serious effect on the engine. This behaviour was investigated in a system safety analysis [15] according to ARP 4761 [20] and confirmed by various regulations of CS-25 [10] and CS-E [11].

\section{Evaluation and Interpretation of the FHR-Liner Rating}

A comparison of Figure $3 a$ and $3 b$ shows that the basic structure of SHR- and FHR-Liners is almost identical. Both liners have a ridged face sheet and back plate with a cell support core in between. This is also shown by the distribution of the degree evaluation criteria fulfilment in Figure 5. Due to the identical structure of the rigid perforated surface in the FHR-Liner, criteria such as "Aerodynamic Quality" (Figure $5 \mathrm{a} ; \mathrm{A} ; \mathrm{m}_{\mathrm{A}, \mathrm{FHR}}=2$ ) or "Environmental Influence" (Figure 5a; $\mathrm{E} ; \mathrm{m}_{\mathrm{E}, \mathrm{FHR}}=2$ ) such as rain, snow and sun can be evaluated equally to the SHR-Liner.

As a result of the reduced cross-section wall segments in the FHR-Liner (Figure 3b), there is a change in the load path in the entire liner segment and a reduction of the tolerable maximum loads in the modified wall structures. However, Bubner [19] shows within the framework of static structural analyses of the FHR-Liner geometry that these changes do not represent a significant deterioration. With an expedient positioning of the face sheet fibre direction parallel to the flexible wall structures, the stress on the cell supported core can be significantly reduced. Thus, the stress caused by "Operational Stress" (Figure 5a; O; $\mathrm{m}_{\mathrm{O}, \mathrm{FHR}}=2$ ) can be evaluated similarly to that of the SHR-Liner.

Minor deficits are recorded in the area of "Drainage and Ventilation" (Figure 5a; D; $\mathrm{m}_{\mathrm{D} \text {,FHR }}=2$ ). The possibility of drainage and ventilation is essential for reliability in terms of functionality and system safety. Liquids and gas can penetrate the cell structure of the sandwich core through the perforated top layer and damage the fibre composite structure and flexible foils mechanically, e.g. by freezing, or chemically, e.g. by de-icing fluid. Due to the low TRL, no drainage and ventilation holes have been provided so far in the FHR-Liner prototypes.

Due to the similarity of the FHR-Liner to the SHR-Liner a fast implementation is expected. Furthermore, Knobloch et al. [03] and Höschler et al. [02] show that a pressure difference must exist between adjacent honeycomb cells to ensure a foil deflection and thus a sufficient dissipative intrinsic damping.

Based on the recognition of Knobloch et al. [03], Mischke et al. [30] developed various extended honeycomb core concepts and evaluated them according to their drainage and ventilation properties. A design change of the currently used square based cell structures (FHR-Liner) to a honeycomb structure (SHR-Liner) would result in advantages for drainage, ventilation and manufacturability [30], and also promote the criteria "Operational Stress" (Figure 5a; O; mo,FHR $=2$ ) and "Weight and Design Space" (Figure 5a; W; $\mathrm{m}_{\mathrm{W}, \mathrm{FHR}}=$ 2).

The disadvantages of the implementation in case of "Reliability and Life Cycle Costs" (Figure 5a; R; $\mathrm{m}_{\mathrm{R}, \mathrm{FHR}}=1$ ) are the new flexible foil components. The properties, as well as the long term functional and structural behaviour of the newly developed foil materials cannot yet be described and 


\section{Relative rating of FHR- and PR-Liner on different MEA}

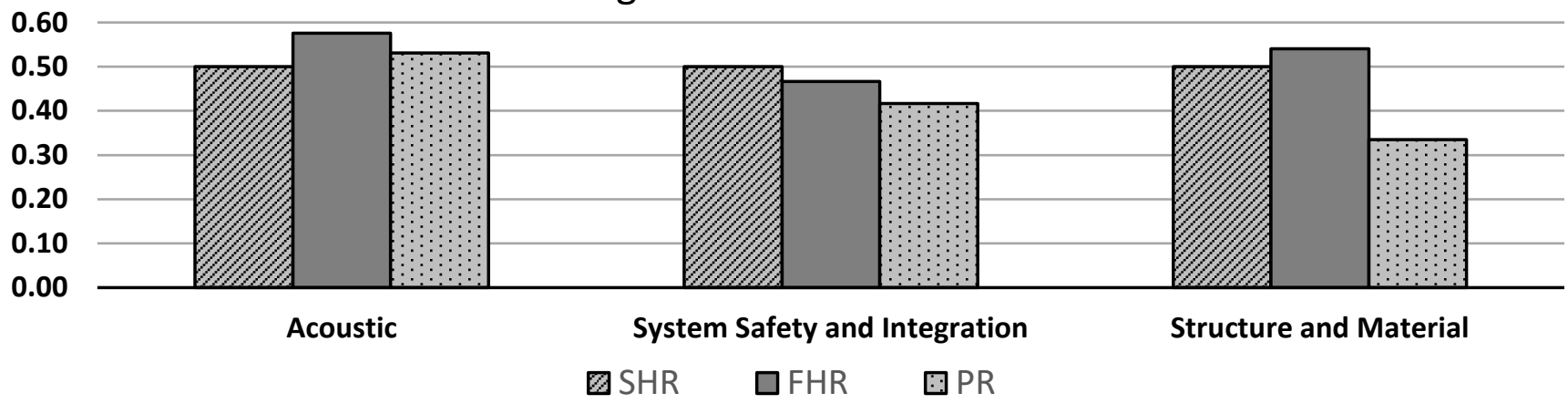

Figure 6: Relative rating of FHR- and PR-Liner on different MEA using weighted point rating method

evaluated sufficiently. However, due to the state of the art, thin elastomer layers tend to change their mechanical properties over a longer period of time under increased environmental influences, e.g. temperature, sun and rain. This assumed behaviour has to be considered during the design for aerospace applications at a desired service life of approximately 20 years [27], [28].

The most distinct advantage of the FHR-Liner can be seen by the criterion "Broadband Attenuation" (Figure 5a; B; $\left.\mathrm{m}_{\mathrm{B}, \mathrm{FHR}}=4\right)$. The principle of action has been proven by Knobloch et al. [03] and is corresponding to the basic purpose of the broadband liner concept. The narrow-band attenuation is slightly worse than that of the SHR-Liner. By adapting the foil materials and optimizing the square based cell structure and the adjacent pressure conditions between them, it is expected to increase the narrow-band damping coefficient almost to that of the SHR-Liner.

\section{Evaluation and Interpretation of the PR-Liner Rating}

The PR-Liner consists of a non-perforated face sheet, a ridged back plate and an intermediate cell support core. Unlike the two Helmholtz resonators, the PR-Liner has a flexible top layer, which is not perforated (Figure 3c). The functionality of the PR-Liner is investigated and described by Kisler et al. [18] and is strongly based on commercial plate resonators [29].

Figure 6 shows clearly that the criterion "Aerodynamic Quality" (Figure 5b; $\mathrm{A} ; \mathrm{m}_{\mathrm{A}, \mathrm{PR}}=4$ ) offers a significant improvement by the PR-Liner compared to the reference liner (SHR-Liner). Although the flexible face sheet oscillates in a range of a few $\mu \mathrm{m}$ [18], [29], the lack of perforation of this face sheet enables a significantly higher aerodynamic quality.

The noise reduction is mainly achieved by effects of plate vibrations e.g. transmission reflection [18], [03] and the increased intrinsic damping (dissipation) of the flexible top layer material. This results in an improvement of the "Broadband Attenuation" (Figure 5b; B; $\mathrm{m}_{\mathrm{B}, \mathrm{PR}}=3$ ) compared to the SHR-Liner. However, the damping coefficient determined by wind tunnel tests is lower than that of the FHR-Liner (Figure 5a; B; $\mathrm{m}_{\mathrm{B}, \mathrm{FHR}}=4$ ) [internal project data; not yet published]. The "Narrowband Noise Reduction" (Figure $5 b ; S ; m_{S, P R}=1$ ) is slightly worse than that of SHRand FHR-Liners due to the missing Helmholtz resonance effect.
The fulfilment of the criteria "Operational Stress" (Figure 5b; B; $\mathrm{m}_{\mathrm{O}, \mathrm{PR}}=1$ ) and "Weight and Design Space" (Figure 5b; $\mathrm{W} ; \mathrm{m}_{\mathrm{B}, \mathrm{PR}}=1$ ) are lower than the reference values of the SHR -Liner and the FHR-Liner (Figure 5a; O; $\mathrm{m}_{\mathrm{O}, \mathrm{FHR}}=2$ ). The base weight of the used flexible foils $\left(\rho_{\text {Folie }} \approx 1080\right.$ to $1200 \mathrm{~kg} / \mathrm{m}^{3}$ ) [34] is similar to the base weight of the fibre reinforced composite layer of the SHR- and FHR-Liner $\left(\rho_{F R C} \approx 1185 \mathrm{~kg} / \mathrm{m}^{3}\right)$ [31], [19]. However, depending on the required foil thickness, the large-area flexible top layer would have a minor weight disadvantage. Due to the flexible foil layer, the face sheet cannot absorb increased loads. The load introduction and transmission of forces and moments in and across the flexible surface is virtually non-existent, which reduces the rating score in the "Operational Stress" area (Figure $5 \mathrm{~b} ; \mathrm{B} ; \mathrm{m}_{\mathrm{O}, \mathrm{PR}}=1$ ). By a reasonable arrangement of the sandwich core structures, the load flow could be at least partially optimized.

The evaluation of "Reliability and Life Cycle Costs" (Figure $5 b ; \mathrm{R} ; \mathrm{m}_{\mathrm{R}, \mathrm{FHR}}=1$ ) and "Drainage and Ventilation" (Figure $5 b ; \mathrm{D} ; \mathrm{m}_{\mathrm{D}, \mathrm{FHR}}=2$ ) are identical to the FHR-Liner. The prototype of the PR-Liner is not including any drainage and ventilation holes. Concerning to the closed face sheet, an active drainage capability is not absolutely necessary. If required, it can be simply integrated into the sandwich core according to the model of the SHR-Liner. The reliability and life cycle costs of the large flexible plate are more critical than the rigid face sheet structures of the SHR-Liner.

Due to the exposed flexible face sheet, the effects of "Environmental Influences" (Figure 5a; R; $\mathrm{m}_{\mathrm{E}, \mathrm{FHR}}=0$ ) are regarded as extremely critical. The chemical influence of sun and rain, as well as chemical fluids during operation on the ground could weaken the thin polymer layer and make it more susceptible to mechanical loads. This could lead to an additional deterioration in the area of "Operational Stress". However, future material adaptations, e. g. chemical additives and fibre reinforcements could provide the sensitive foil material with the required properties for aerospace application.

\section{Evaluation of the Specific MEC and Comparison to the Reference Liner}

The specific rating of the various MECs in Figure 6 clearly shows that both new broadband liner concepts have an advantage in the MEC "Acoustic" $\left(F H R_{M E A_{-} A}=0.58\right.$, 
$\left.P R_{M E A_{-} A}=0.53\right)$ over the reference product $\left(S H R_{M E A_{-} A}=\right.$ $0.50)$. Despite the low TRL, a high potential of the new broadband liner concepts can already be estimated.

However, the specific rating in the category "Safety and Integration" is in favour of the established SHR-Liner $\left(F_{M E A_{-} S I}=0.47, P R_{M E A_{-} S I}=0.42, S H R_{M E A_{-} S I}=0.50\right)$. However, this presents only a slight deficit and can be improved by

- $\quad$ application of drainage and ventilation holes (FHRand PR-Liner),

- $\quad$ adaptation of the fibre layer direction in the rigid perforated face sheet (FHR-Liner),

- improvement of foil properties within the scope of chemical and mechanical resistance (FHR- and PR-Liners) and

- a variation of the topological and geometric shape of the sandwich core (FHR- and PR-Liner).

The combination of functionality and safety is also reflected in the specific ranking at the MEC "Structure and Material". As a result of the high similarity to the SHR-Liner, e.g. composition and structural behaviour, as well as the clear advantage in broadband noise reduction, the rating of the FHR-Liner is higher than that of the SHR-Liner $\left(F H R_{M E A_{-} S M}=0.53, S H R_{M E A_{-} S M}=0.50\right)$.

Due to its large exposed and flexible face sheet and the poorer values in the narrowband (compared to SHR- and FHR-Liner) and broadband attenuation (compared to FHR-Liner), the PR-Liner is rated lower than the other solutions $\left(P R_{M E A \_S M}=0.33\right)$.

However, these disadvantages can be significantly reduced by the implementation of the optimization possibilities already mentioned

\section{CONCLUSION}

This paper presents an approach to product rating and evaluation of different product solutions for broadband attenuation acoustic liner concepts for aerospace application. In the process, corresponding requirements have been defined for the considered system and evaluation criteria have been derived. Three MECs:

- Acoustics,

- System Safety and Integration, and

- $\quad$ Structure and Material

have been introduced to not falsify the assessment results by subject-specific exclusion criteria.

The ranked space method according to Breiing and Knosala [24] has been selected for weighting the evaluation criteria to ensure an objective and knowledge-based rating. The rating has been carried out by a weighted point rating, which has been conducted by the project partners with different fields of expertise.

The interpretation of the results and the comparison with the currently in service SHR-Liners show the high demands on aeronautical systems. Concise operational requirements and previously not considered system functions have been identified and linked to the rating and evaluation process.
Building on this, further steps for the optimisation and development of the acoustic liner concepts have been presented and explained.

The specific ranking results on the three MECs significantly shows the potential and future direction of research and development for broadband effective acoustic liners with flexible structures for aviation application.

\section{ACKNOLEDGEMENT}

The work presented in this paper is part of the joint project LaKS (Lärmabsorbierende Kunststoffstrukturen; Noise Absorbing Composite Structures) founded through the LuFO V-2 programme of the German Federal Ministry of Economics and Energy, under the contract No. 20E1502.

My thanks also go to the colleagues and project partners from the DLR - Department of Engine Acoustics (Lars Enghardt, Karsten Knobloch, Friedrich Bake), from the TU Dresden - Institute for Lightweight Engineering and Polymer Technology (Niels Modler, Martin Dannemann, Michael Kucher, Eckart Kunze), to the TU Berlin - Department of Technical Acoustics (Ennes Sarradj, Roman Kisler) and to the Fraunhofer Institute - Department for Polymer Materials and Composites (Christoph Uhlig, Olaf Kahle). Without the cooperation and mutual support of the different disciplines, the concept study, rating and evaluation would not have been possible in this framework.

\section{REFERENCES}

[01] European Commission (2011): Flightpath 2050 Europe's vision for aviation; Publ. Off. of the Europ. Union, (Lux), DOI: 10.2777/50266

[02] Hoeschler K., Sarradj E., Modler N., Enghardt L. (2018): Novel Jet Engine Acoustic Liner with improved Broadband Noise Absorbing; 31st ICAS 2018, Belo Horizonte (BRA), In Press

[03] Knobloch K., Enghardt L., Bake F. (2018): Helmholtz Resonator Liner with Flexible Walls; 24th AIAA/CEAS Aeroacoustics Conference 2018, Atlanta (USA), DOI: $10.2514 / 6.2018-4102$

[04] Ehrlenspiel K. (2009): Integrierte Produktentwicklung; Munich (GER), Carl Hanser Verlag, DOI: 10.3139/978$3-446-42157-8$

[05] Verein Deutscher Ingenieure (1993): VDI 2221 Methodik zum Entwickeln und Konstruieren technischer Systeme und Produkte; Dusseldorf (GER), Beuth Verlag $\mathrm{GmbH}$

[06] Lindemann U. (2007): Methodische Entwicklung technischer Produkte; Berlin (GER), Springer-Verlag, DOI: $10.1007 / 978-3-540-37451-0$

[07] Berding J. (2016); Entwicklung eines wandlungsfähigen Pressensystems mit Servospindelantrieb; Cottbus (GER), BTU Cottbus-Senftenberg, ISBN: 978-3-86624633-1 
[08] Bertsche B., Lechner G. (2004): Zuverlässigkeit im Fahrzeug- und Maschinenbau; Berlin (GER), SpringerVerlag, DOI: 10.1007/3-540-34996-0

[09] Feldhusen J., Grote K. (2013): Pahl/Beitz Konstruktionslehre; Springer-Verlag, Berlin (GER), DOI: 10.1007/978-3-662-09186-9

[10] European Aviation Safety Agency (2017): Certification Specification and Acceptable Means of Compliance for Large Aeroplanes (CS-25) - Amdt 20; Cologne (GER), EASA

[11] European Aviation Safety Agency (2015): Certification Specification and Acceptable Means of Compliance for Engines (CS-E) - Amdt. 4; Cologne (GER), EASA

[12] European Aviation Safety Agency (2016): Certification Specification and Acceptable Means of Compliance and Guidance Material for Aircraft Noise (CS-36) - Amdt. 4; Cologne (GER), EASA

[13] Kazula S., Höschler K. (2017): A systems engineering approach to variable intakes for civil aviation; EUCASS 2017, Milan (ITA), DOI: 10.13009/EUCASS2017-20

[14] Kazula S, Höschler K. (2018): Ice Detection and Protection Systems for Circular Variable Nacelle Inlet Concepts; DLRK 2018, Friedrichshafen (GER)

[15] Mischke M., Kazula S., Höschler K. (2019): Preliminary Safety Assessment on System Design Level for Broadband Acoustic Liner Concepts for Aviation; ISABE 2019, Canberra (AUS), In Press

[16] Verein Deutscher Ingenieure (1996): VDI 2803 Funktionsanalyse - Grundlagen und Methoden; Dusseldorf (GER), Beuth Verlag GmbH

[17] SAE International (SAE Aerospace) (2010): ARP 4754 Guidelines for Development of Civil Aircraft and Systems; Warrendale (USA), SAE International

[18] Kisler R., Sarradj E. (2017): Plate Silencers for Broadband Low Frequency Sound Attenuation; Acta Acoustica united with Acoustica, Berlin (GER), DOI: 10.3813/AAA.919194

[19] Bubner T. (2018): Homogenisierung und Strukturanalyse von komplexen Wabenkernstrukturen für Sandwichstrukturen neuartiger AkustiklinerKonzepte für die luftfahrttechnische Anwendung; Cottbus (GER), BTU Cottbus-Senftenberg

[20] SAE International (SAE Aerospace) (1996): ARP 4761 Guidelines and Methods for conducting the safety assessment progress on civil airborne systems and equipment; Warrendale (USA), SAE International

[21] Grasselt D., Höschler K., Kazula S. (2017): A Design Approach for a Coupled Actuator System for Variable Nozzles and Thrust Reverser of Aero Engines; ISABE 2017 (Manchester, GBR), ISABE-2017-21450

[22] Kazula S., Grasselt D., Mischke M., Höschler K. (2018): Preliminary Safety Assessment of Circular Variable Nacelle Inlet Concepts for Aero Engines in Civil
Aviation, Safety and Reliability - Safe Societies in a Changing World; London: CRC Press, pp. 2459-2269, ISBN: 9781351174657

[23] Kazula S., Grasselt D., Höschler K. (2018): Common cause analysis of circular variable nacelle inlet concepts for aero engines in civil aviation; IRF 2018, Lisbon (POR), ISBN: 978-989-20-8313-1

[24] Breiing A., Knosala R. (1997): Bewerten technischer Systeme; Berlin (GER), Springer-Verlag, DOI: 10.1007/978-3-642-59229-4

[25] Verein Deutscher Ingenieure (1998): VDI2225 Blatt 3 Konstruktionsmethodik - Technisch-wirtschaftliches Konstruieren -Technisch wirtschaftliche Bewertung; Dusseldorf (GER), Beuth Verlag GmbH

[26] Zangemeister C. (1970): Nutzwertanalyse in der Systemtechnik; Berlin (GER), TU Berlin

[27] Rolls-Royce Plc (2015): The jet engine; Chichester (GBR), Wiley, ISBN: 978-1-119-06599-9

[28] W. J. G. Bräunling W. (2015): Flugzeugtriebwerke; Berlin (GER): Springer-Verlag, DOI: 10.1007/978-3642-34539-5

[29] Fuchs H. (2010): Schallabsorber und Schalldämpfer; Berlin (GER), Springer-Verlag, DOI: 10.1007/978-3540-35622-6

[30] Mischke M., Kazula S., Pohl M., Höschler K. (2019): Concept Development and Evaluation for a Broadband Noise Absorbing Acoustic Liner Concept for Aviation; ISABE 2019, Canberra (AUS), In Press

[31] F. Hähnel (2015): Ein Beitrag zur Simulation des Versagens von Honigwaben aus Meta-Aramid-Papier in schlagbelasteten Sandwich-Strukturen; Dresden (GER), Shaker-Verlag, ISBN: 978-3-844-04366-2

[32] Azimi M., Ommi F., Alashti N. (2014): Using Acoustic Liner for Fan Noise Reduction in Modern Turbofan Engines; IJASS 15(1), 97-101 (2014), DOI:10.5139/IJASS.2014.15.1.97

[33] NASA (2002): Advanced Nacelle Acoustic Lining Concepts Development; Hampton/Virginia (USA), NASA/CR-2002-211672

[34] BASF Polyurethanes GmbH (2016): ELASTOLLAN® Datasheet - Thermoplastische Polyurethan-Elastomere (TPU); Lemförde (GER), http://www.polyurethanes.basf .de/pu/elastollan/Infomaterial 